\title{
Synergistic Effect of Antithrombin III, Activated Protein C and Heparin on the Inhibition of the Tissue Thromboplastin-Mediated Coagulation
}

\author{
Keizo Hirahara, ${ }^{*, a}$ Yuko EtoH, ${ }^{a}$ Tetsuro Matsuishi, ${ }^{a}$ Nobuo Suzuki ${ }^{a}$ and Munetsugu Kurata ${ }^{b}$ \\ Pharma Research Laboratories, Hoechst Japan Ltd., '3-2, 1-chome, Minamidai, Kawagoe, Saitama 350, Japan and Faculty of Pharmaceutical Sciences,
} Josai University, ${ }^{b}$ Keyakidai, Sakado, Saitama 350-02, Japan. Received August 23, 1988

The synergistic effect of antithrombin III (ATII), activated protein C (APC) and heparin on the tissue thromboplastin (TP)-mediated coagulation cascade was studied. APC prolonged the activated partial thromboplastin time of human plasma with increasing APC concentration but affected the prothrombin time only slightly. Neither ATIII nor heparin prolonged the prothrombin time by itself, while a mixture of APC and heparin strongly inhibited the coagulation. When the effects of APC, heparin and ATIII on the TP-mediated coagulation were examined with a solution consisting of prothrombin, factor $\mathrm{V}$, factor VII, factor $\mathrm{X}$ and fibrinogen at physiological concentrations, the coagulation time was prolonged only slightly by the APC-heparin or ATIII-heparin mixture. However, the coagulation time was prolonged markedly by simultaneous addition of APC, ATIII and heparin to the solution. Inhibition of thrombin activity by the ATIII-APC-heparin mixture was weak as compared with that by the ATIII-heparin mixture after a 1-min incubation, but after a 2-min incubation the inhibitory activities were equal. Suppression of thrombin activity by the ATIII-APC-heparin mixture was supposed to be due to the inhibition of the interaction between ATIII and heparin on thrombin by APC because the APC-ATIII-heparin complex was detected by crossed immunoelectrophoresis but not by sodium dodecyl sulfate (SDS)-polyacrylamide electrophoresis. When the inhibitory effect of APC alone or the APC-heparin mixture on the platelet prothrombin converting activity (PPCA) was examined, heparin accelerated the PPCA inhibition by APC. These results suggested that the coexistence of APC, ATIII and heparin was essential in the modulation of the TP-mediated coagulation cascade and that the APC-ATIII-heparin, APC-heparin and ATIII-heparin complexes also play an important role in the modulation of the TP-mediated coagulation cascade.

Keywords antithrombin III; protein C; heparin; tissue thromboplastin; APC-ATIII-heparin complex

Antithrombin III (ATIII) is one of the plasma protease activity-inhibiting proteins which participate in the control and regulation of the blood coagulation cascades and it is currently used for treatment of disseminated intravascular coagulation (DIC). ${ }^{1-3)}$ ATIII inactivates thrombin, as the name indicates, and other coagulation factors such as factor Xa (FXa) and factor IXa (FIXa) in vitro., ${ }^{4,5)}$ As reported by Miletich et al. ${ }^{6)}$ and Lindhout et al. ${ }^{7}{ }^{7}$ however, the activity of FXa that has formed complexes with FVa, $\mathrm{Ca}^{2+}$ and phospholipids is not abrogated by ATIII and heparin. It is likely that the control and regulation of the plasma coagulation cascade by ATIII and heparin are mainly owing to the inhibition of thrombin activity and that these agents do not fully inactivate the coagulation cascade. In our in vitro preliminary test, ATIII did not affect the tissue thromboplastin (TP)-mediated coagulation cascade even in the presence of heparin. This result again suggested that ATIII and heparin do not fully inhibit the TP-mediated coagulation cascade. Furthermore, the activity of ATIII is inhibited by TP and phospholipids in the presence of heparin as reported by Ofosu et al. ${ }^{8)}$ and abrogated strongly by fatty acids as reported by Hirahara et al..$^{9,10)}$ In our studies to find more effective anticoagulant agents, combined use of activated protein C (APC), heparin and ATIII was found to exhibit a very potent anticoagulant activity that cannot be obtained with APC alone or the ATIII-heparin mixture. We examined the modes of action of APC, ATIII and heparin in the regulation of the TPmediated coagulation pathway and clarified a new regulation mechanism of the coagulation cascade; inhibition of prothrombinase generation by APC and heparin reduces thrombin generation, and then ATIII and heparin inhibit thrombin activity efficiently.

\section{Materials and Methods}

Materials Human prothrombin, human coagulation factor VII (FVII), bovine factor X (FX), Russell's viper venom-activated bovine factor $\mathrm{Xa}(\mathrm{FXa})$ and human thrombin were purchased from Sigma Co. (St. Louis, U.S.A.), bovine factor V (FV), from Enzyme Research Laboratory (Calfornia, U.S.A.), and heparin and fibrinogen, from Green Cross Co., Ltd. (Osaka, Japan). Veronal buffer solution ( $\mathrm{pH} 7.6$ ), tissue thromboplastin (TP) from human placenta, bovine serum albumin (BSA), a synthetic substrate for determination of thrombin activity (BCP-100, Dphenyl-prolyl-arginyl-5-amino-2-nitrobenzoic acid isopropylamide), protein $\mathrm{C}$ activator (Protac ${ }^{\circledR}$ ) and human antithrombin III were provided by Behringwerke AG (Marburg, FRG). Human protein C (PC) was purified from the prothrombin complex (Beriplex ${ }^{\circledR}$, Behringwerke AG, Marburg, FRG) by Kisiel's method.11 A PC-containing fraction was pooled, concentrated by ultrafiltration to about $1 \mathrm{mg} / \mathrm{ml}$, and frozen at $-80^{\circ} \mathrm{C}$ until use. The protein concentration was determined from its optical density at $280 \mathrm{~nm}$ using an extinction coefficient of $14.5(1 \%, 1 \mathrm{~cm}$, $280 \mathrm{~nm}) .^{12)}$ Activated PC (APC) was prepared with Protac ${ }^{\circledR}$ by an incubation for $4 \mathrm{~min}$ at $37^{\circ} \mathrm{C}$.

Measurement of Prothrombin Time (PT) for Estimation of Anticoagulant Activity A modification of Suzuki's method ${ }^{13)}$ was used. To $100 \mu$ l of human pooled plasma, $100 \mu \mathrm{l}$ of $\operatorname{APC}(2.5,5.0$ and $10.0 \mu \mathrm{g} / \mathrm{ml})$ and $100 \mu \mathrm{l}$ of heparin $(0.5 \mathrm{U} / \mathrm{ml})$ were added, and the mixtures were incubated at $37^{\circ} \mathrm{C}$ for $1,2,3,4,5,8$ and $10 \mathrm{~min}$. After the addition of $100 \mu \mathrm{l}$ of TP containing $25 \mathrm{mM} \mathrm{CaCl}_{2}$, the clotting time was measured by use of a fibrin timer (Behringwerke AG). Separately, human prothrombin, FVII, FX, FV and fibrinogen were diluted with veronal buffer solution containing $0.2 \%$ BSA so that the final concentration might be $0.4 \mathrm{mg} / \mathrm{ml}$ for fibrinogen, $0.2 \mathrm{mg} / \mathrm{ml}$ for prothrombin, $0.4 \mu \mathrm{g} / \mathrm{ml}$ for FVII, $250 \mu \mathrm{g} / \mathrm{ml}$ for $\mathrm{FV}$ and $7.5 \mu \mathrm{g} / \mathrm{ml}$ for FX. To $150 \mu \mathrm{l}$ each of them, $50 \mu \mathrm{l}$ of ATIII $(3 \mu \mathrm{M}), 50 \mu \mathrm{l}$ of $\operatorname{APC}(2.5 \mu \mathrm{g} / \mathrm{ml})$ and $50 \mu \mathrm{l}$ of heparin $(0.5 \mathrm{U} / \mathrm{ml})$ were added, and the mixtures were incubated at $37^{\circ} \mathrm{C}$ for $4 \mathrm{~min}$. After the addition of $100 \mu \mathrm{l}$ of TP containing $25 \mathrm{mM} \mathrm{CaCl}_{2}$, the clotting time was measured in a similar manner. On this occasion, the effects of ATIII, APC, heparin, ATIII+ APC, ATIII + heparin and APC + heparin were examined.

The amount of generated thrombin was measured as follows: with 5,10 , 15 and $20 \mathrm{U} / \mathrm{ml}$ of human thrombin a calibration curve was drawn by plotting the clotting time as the ordinate and the thrombin concentration as the abscissa; and the amount of generated thrombin was calculated from the calibration curve. 
Measurement of Activated Partial Thromboplastin Time (APTT) for Estimation of ATIII Anticoagulant Activity in the Presence of Heparin A modification of the method of Löbermann et al. ${ }^{14)}$ was adopted. To $100 \mu \mathrm{l}$ of human pooled plasma, $50 \mu \mathrm{l}$ of heparin $(0.125,0.25,0.5,0.75$ and $1.0 \mathrm{U} / \mathrm{ml}$, prepared with veronal buffer solution containing $0.2 \% \mathrm{BSA}$ ) was added, and the mixtures were incubated at $37^{\circ} \mathrm{C}$ for $2 \mathrm{~min}$. Immediately after the addition of $50 \mu \mathrm{l}$ of phospholipid solution containing kaolin (Pathromtin ${ }^{\circledR}$, Behringwerke AG, FRG) and $50 \mu \mathrm{l}$ of $25 \mathrm{mM} \mathrm{CaCl}_{2}$, the clotting time was measured with a fibrin timer.

Inhibition of Human Thrombin Activity by ATIII and Heparin in the Presence or Absence of APC The inhibitory activity of ATIII and heparin on thrombin activity was determined by the method of Hirahara et al. ${ }^{10}$ )

Inhibition of Prothrombin Converting Activity by APC in the Presence or Absence of Heparin A modification of the method of Comp and Esmon was used. ${ }^{15)}$ Gel-filtered rabbit platelet suspension was diluted to $10^{8} / \mathrm{ml}$ with $0.15 \mathrm{M} \mathrm{NaCl}$ and $20 \mathrm{~mm}$ Tris- $\mathrm{HCl}$ buffer solution ( $\mathrm{pH} 7.4$ ) containing BSA $(2 \mathrm{mg} / \mathrm{ml})$, and to $50 \mu \mathrm{l}$ of the diluted platelets, $5 \mu \mathrm{l}$ of human thrombin $(10 \mathrm{U} / \mathrm{ml})$ was added. After incubation at $37^{\circ} \mathrm{C}$ for $2 \mathrm{~min}, 50 \mu \mathrm{l}$ of $25 \mathrm{mM} \mathrm{CaCl} \mathrm{C}_{2}$ was added, and $60 \mathrm{~s}$ later, $50 \mu \mathrm{l}$ of APC $(2.5 \mu \mathrm{g} / \mathrm{ml})$ in the presence or absence of heparin $(0.5 \mathrm{U} / \mathrm{ml})$ was added. After a 1-, 5-, 10- or 20-min incubation, $50 \mu \mathrm{l}$ of FXa $(2 \mu \mathrm{g} / \mathrm{ml})$ was added. The mixtures were incubated for $1 \mathrm{~min}$ and then $50 \mu \mathrm{l}$ of prothrombin $(200 \mu \mathrm{g} / \mathrm{ml})$ was added. After a $60-\mathrm{s}$ incubation, they were centrifuged at $2000 \mathrm{rpm}$ at $4^{\circ} \mathrm{C}$ for $20 \mathrm{~min}$. Supernatants were collected and diluted 50 fold with $0.1 \mathrm{M}$ Tris- $\mathrm{HCl}$ buffer solution $(\mathrm{pH} 8.3$ ). A $1-\mathrm{ml}$ portion of the 50 -fold dilution was mixed with $2 \mathrm{~mm}$ BCP- 100 in $0.1 \mathrm{M}$ Tris-HCl buffer

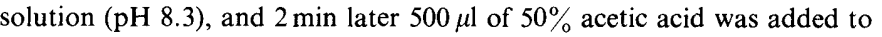
stop the reaction, and the absorbance at $405 \mathrm{~nm}$ was measured.

Two-Dimensional Immunoelectrophoresis The test was done according to Ressler's method. ${ }^{16)}$ Horizontal agarose gel electrophoresis was run using $0.025 \mathrm{M}$ veronal buffer solution ( $\mathrm{pH} 8.6$ ) as electrophoresis buffer. Two-dimensional immunoelectrophoresis was carried out using antiprotein $\mathrm{C}$ antiserum from rabbit $(3 \% \mathrm{v} / \mathrm{v})$ and anti-ATIII antiserum from rabbit $(4 \% \mathrm{v} / \mathrm{v})$ in $1 \%$ agarose in the second dimension. A $50-\mu \mathrm{l}$ portion of ATIII $(50 \mu \mathrm{M})$ was supplemented with $50 \mu \mathrm{l}$ of APC $(0.3 \mathrm{mg} / \mathrm{ml})$ in the presence or absence of heparin $(100 \mathrm{U} / \mathrm{ml})$ containing $8 \mathrm{mM} \mathrm{CaCl}_{2}$, and the mixture was incubated at $37^{\circ} \mathrm{C}$ for $10 \mathrm{~min}$. Then, $15 \mu \mathrm{l}$ of each reaction mixture was withdrawn and subjected to two-dimensional immunoelectrophoresis with anti-protein $\mathrm{C}$ and/or anti-ATIII antiserum in the second dimension. After washing, drying and staining, the slides were photographed.

\section{Results}

Effect of Heparin on PT and APTT of Human Plasma Since ATIII inhibits the activity of thrombin rapidly in the presence of heparin, ${ }^{17,18)}$ the effect of heparin on the

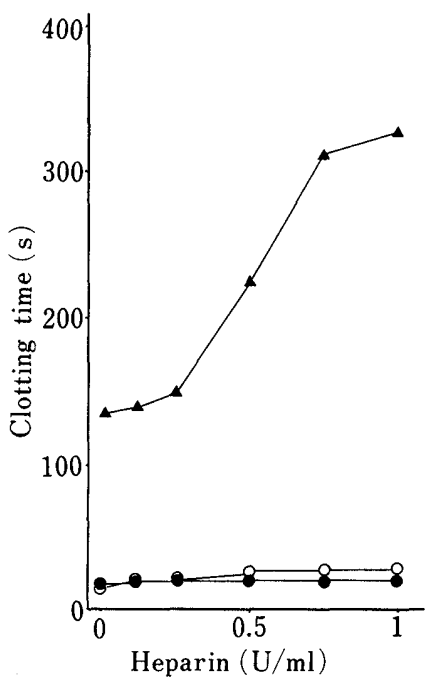

Fig. 1. Effect of Heparin on APTT and PT in Plasma

$\Delta$, APTT reagent was added to the mixture of plasma and heparin after a 2-min incubation at $37^{\circ} \mathrm{C} ; \boldsymbol{\varphi}, \mathrm{PT}$ reagent was added to the mixture of plasma and heparin after a 2-min incubation at $37^{\circ} \mathrm{C} ; \mathrm{O}, \mathrm{PT}$ reagent was added to the mixture of plasma and heparin after a 10 -min incubation at $37^{\circ} \mathrm{C}$. extrinsic and intrinsic coagulation cascades in plasma was examined. As shown in Fig. 1, the PT was not prolonged irrespective of an incubation after heparin addition, while the APTT was prolonged with increasing heparin concentration. These results suggested that the TP-mediated coagulation cascade may be regulated by some other factor

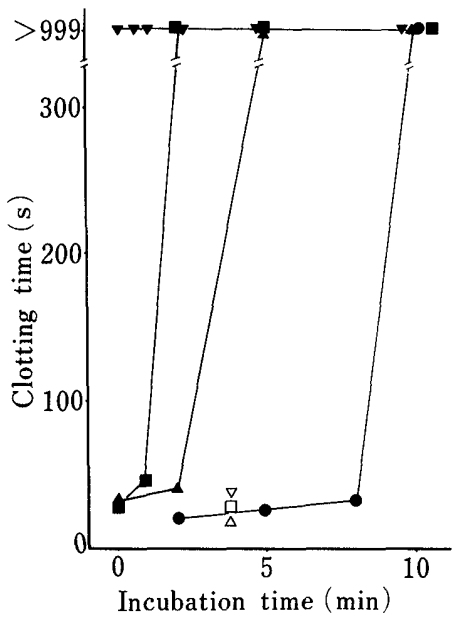

Fig. 2. Effect of APC in the Presence of $0.5 \mathrm{U} / \mathrm{ml}$ Heparin on PT in Plasma

PT reagent was added to a mixture of APC and plasma after selected time periods at $37^{\circ} \mathrm{C}(\triangle$ and $\Delta, 2.5 \mu \mathrm{g} / \mathrm{ml} \mathrm{APC} ; \square$ and, $5.0 \mu \mathrm{g} / \mathrm{ml} \mathrm{APC} ; \nabla$ and $\nabla, 10.0 \mu \mathrm{g} / \mathrm{ml}$ APC). Closed symbols represent the presence of heparin and open symbols, the absence of heparin. , PT reagent was added to the plasma after a selected time of activation with Protac ${ }^{8}$ at $37^{\circ} \mathrm{C}$ in the presence of heparin.

TABLE I. Inhibition of TP-Mediated Coagulation Cascade by APC, ATIII and Heparin

\begin{tabular}{|c|c|c|c|}
\hline \multirow{2}{*}{ Sample } & \multirow{2}{*}{$n$} & \multicolumn{2}{|c|}{ Clotting time (s) } \\
\hline & & Mean & S.D. \\
\hline $\mathrm{APC}+$ heparin $+\mathrm{ATIII}$ & 6 & 55.6 & \pm 8.5 \\
\hline APC & 6 & 19.6 & \pm 1.4 \\
\hline ATIII & 6 & 14.8 & \pm 0.8 \\
\hline ATIII + heparin & 6 & 21.2 & \pm 2.3 \\
\hline $\mathrm{ATIII}+\mathrm{APC}$ & 5 & 20.1 & \pm 0.9 \\
\hline $\mathrm{APC}+$ heparin & 6 & 22.7 & \pm 1.8 \\
\hline Heparin & 6 & 16.2 & \pm 1.4 \\
\hline
\end{tabular}

In this experiment, $2.5 \mu \mathrm{g} / \mathrm{ml} \mathrm{APC}, 3 \mu \mathrm{M}$ ATIII and $0.5 \mathrm{U} / \mathrm{ml}$ heparin were used.

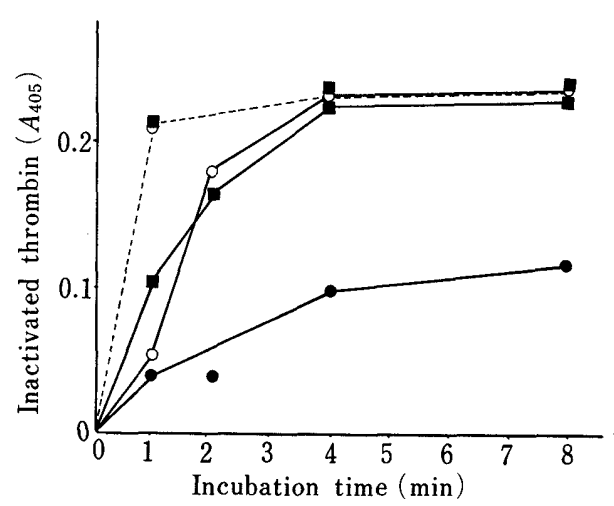

Fig. 3. Inhibitory Effect of ATIII and Heparin in the Presence or Absence of APC on Thrombin

O, ATIII $(3 \mu \mathrm{M})+$ APC $(2.5 \mu \mathrm{g} / \mathrm{ml})+$ heparin $(0.5 \mathrm{U} / \mathrm{ml}) ; \quad$ ATIII $(3 \mu \mathrm{M})+$ heparin $(0.5 \mathrm{U} / \mathrm{ml}) ; 0$, ATIII $(3 \mu \mathrm{M})$ alone. Dotted lines denote absence of tissue thromboplastin. 
A

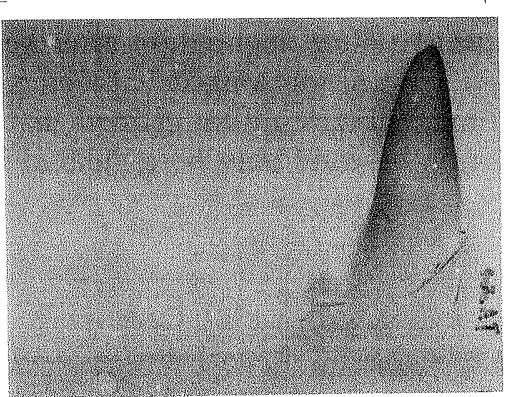

B

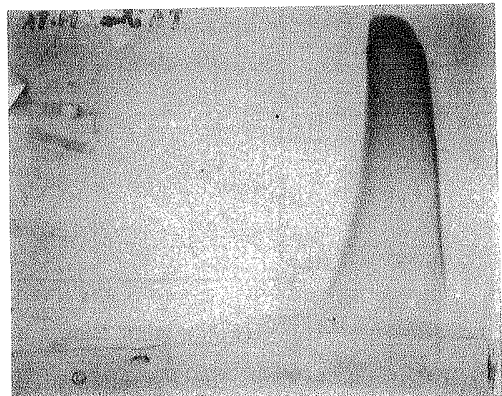

C
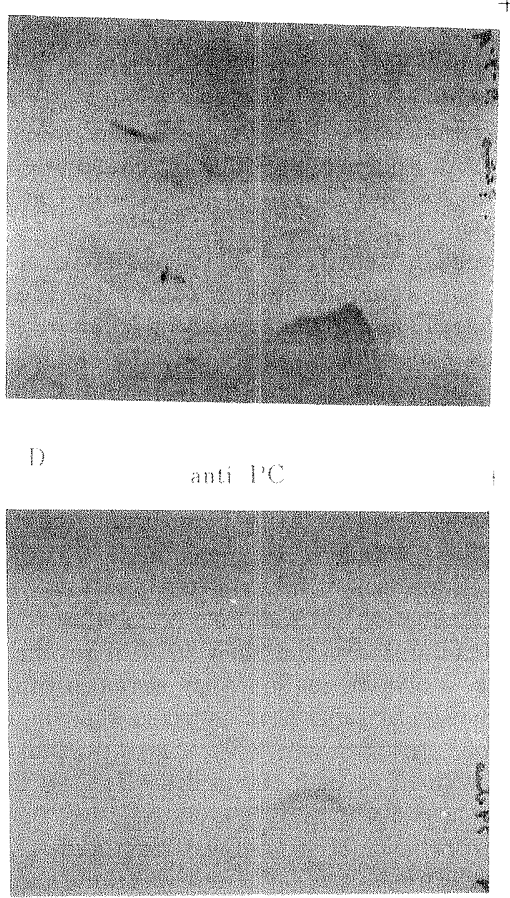

Fig. 4. Two-Dimensional Immunoelectrophoresis

A ATIII $(50 \mu \mathrm{M})+$ heparin $(100 \mathrm{U} / \mathrm{ml})+$ APC $(300 \mu \mathrm{g} \mathrm{ml})$ with anti-human ATIII: B. ATIII $(50 \mu \mathrm{M})+$ heparin $(100 \mathrm{U} / \mathrm{ml})$ with anti-human ATIII: C. ATIII $(50 \mu \mathrm{m})+$ heparin $(100 \mathrm{U} / \mathrm{ml})+\mathrm{APC}(300 \mu \mathrm{g} / \mathrm{ml})$ with anti-human $\mathrm{PC}: \mathrm{D}$, APC $(300 \mu \mathrm{g} / \mathrm{ml})+$ heparin $(100 \mathrm{U} / \mathrm{ml})$ with anti-human PC. Application volume was $15 \mu \mathrm{l}$.

than heparin in relation to the expression of the anticoagulant activity of ATIII. Then, the effect of PC, another factor playing an important role in the coagulation cascade on the PT was examined.

Effect of Activated Protein $\mathrm{C}$ on $\mathrm{PT}$ in the Presence of ATIII or Heparin APC $(2.5,5.0$ and $10.0 \mu \mathrm{g} / \mathrm{ml})$ was added to human plasma in the presence of heparin $(0.5 \mathrm{U} / \mathrm{ml})$. After incubation at $37 \mathrm{C}$, TP containing $\mathrm{CaCl}_{2}$ was added, and the clotting time was measured. As Fig. 2 shows, the PT was clearly prolonged. Prolongation of the PT was also observed upon addition of $\mathrm{CaCl}_{2}$-containing TP after activation of protein $C$ in plasma with Protac ${ }^{\circledR}$. However, the inhibitory activity of APC on the TPmediated coagulation in the absence of heparin was considerably less potent than in the presence of heparin.

As the above-mentioned experiments were done with plasma, a possible influence of other factors could not be ruled out. Therefore, prolongation of the PT was examined by adding ATIII, heparin and APC to a solution consisting of FV, FX, prothrombin, FVII and fibrinogen. As shown in Table I, the PT was considerably prolonged in the presence of APC, ATIII and heparin. The prolongation could not be attained by APC alone or ATIII + heparin, but the effect of APC ' with heparin was a little stronger than that of APC alone. The inhibited generation of thrombin in the presence of APC, heparin and ATIII was calculated to be $0.5 \mathrm{U} / \mathrm{ml}$ from the calibration curve prepared previously. To examine whether this value was attributed to the inhibition of thrombin generation, inhibition of thrombin activity, or both, the effect of APC on the inhibition of thrombin activity was examined first.

Inhibitory Effects of ATIII and Heparin on Thrombin in the Presence or Absence of APC The inhibitory activities

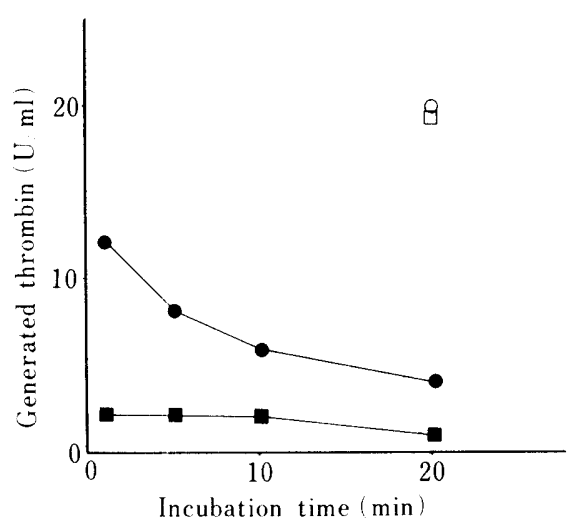

Fig. 5. Effect of APC or APC + Heparin on Platelet ProthrombinConverting Activity

O. $\operatorname{APC}(2.5 \mu \mathrm{g} / \mathrm{ml})$ alone; $\square, \operatorname{APC}(2.5 \mu \mathrm{g} / \mathrm{ml})+$ heparin $(0.5 \mathrm{U} / \mathrm{ml}): \bullet$. heparin $(0.5 \mathrm{U} / \mathrm{ml})$ alone: $\mathbf{D}$. medium

of ATIII and heparin on thrombin activity were measured by use of a synthetic substrate. As shown in Fig. 3, there was no difference in the inactivation of thrombin by ATIII and heparin in the presence and absence of APC after a 2min incubation. After a 1-min incubation, however, the thrombin inactivation by ATIII + heparin was suppressed in the presence of APC. The inhibition of thrombin activity proceeded promptly in the absence of $\mathrm{TP}$, and the presence or absence of APC did not affect the inhibition of thrombin activity after a $1-\mathrm{min}$ incubation.

Based on the above results and the fact that either of ATIII and PC combined with heparin, ${ }^{17-19)}$ complex formation in the mixtures of APC, ATIII and heparin was examined by two-dimensional electrophoresis. As Fig. 4 
shows, a peak $(\downarrow)$ was observed on the negative side $(-)$ of the ATIII-heparin complex, suggesting formation of a complex among APC, ATIII and heparin. This complex could not be detected by sodium dodecyl sulfate (SDS)polyacrylamide electrophoresis (PAGE) using western blotting, and the interaction of APC with ATIII and heparin was estimated to be very weak (data not shown).

Next, the inhibitory effects of APC and APC + heparin on prothrombinase generation were examined.

Effects of APC and APC + Heparin on Platelet Prothrombin Converting Activity As Fig. 5 shows, the generation of prothrombinase was strongly suppressed by APC in the presence of heparin as compared with APC alone. Heparin caused no effect by itself on the prothrombinase generation even after a 20 -min incubation.

\section{Discussion}

Since FXa usually forms complexes with $\mathrm{FVa}, \mathrm{Ca}^{2+}$ and phospholipids to function as prothrombinase in the living body, ATIII is considered to express its in vivo anticoagulant activity mainly by the inhibition of thrombin activity and to have less potent activity in inactivation of the coagulation cascade. ${ }^{6,7)}$ Insufficient inhibition of thrombin activity by ATIII may cause thrombosis. In fact, it is well known that decrease of blood ATIII levels causes severe coagulation disturbances. ${ }^{1,4)}$

At present, ATIII preparations are used for treatment of DIC, which is in part caused by tissue thromboplastin-like material. ${ }^{1-3)}$ In the in vitro experiment, however, the PT was not prolonged by ATIII + heparin at all, as shown in Fig. 1, and ATIII + heparin seemed not to show any effect on the TP-mediated coagulation cascade. That is, the ATIII preparation is assumed to be apparently effective owing to other anticoagulant factors in the living body. Further, PC as well as ATIII has been reported to cause thrombosis when its anticoagulant activity is low. ${ }^{20)}$ So, the participation of PC in the regulation of the TP-mediated coagulation cascade was examined.

$\mathrm{PC}$ is known as an anticoagulant which is activated by thrombomodulin and thrombin, decomposes FVa and FVIIIa proteolytically, and as a result inhibits thrombin generation in the living body. ${ }^{21-23)}$ In human plasma, APC significantly prolongs the APTT and the prolongation of the APTT is used as an index in the assay system for PC. However, APC did not affect the PT by itself as shown in Fig. 2. This result may suggest that thrombin is generated due to insufficient inhibition of FVa activity by APC and that the generated thrombin was not sufficiently inhibited by protease inhibitors (PI's) including ATIII. However, in the absence of heparin, ATIII does not exhibit any function as an apparent PI on the prolongation of the APTT, ${ }^{24)}$ and the inhibition of thrombin activity by ATIII alone is regarded not to be physiological in the regulation of the coagulation cascade because heparin-like materials are found on the endothelial cells and because the function of ATIII is considered to be expressed via those materials. ${ }^{25,26)}$ This fact indicates the necessity of the interaction of ATIII, heparin and APC. Then, we examined the inhibition of the TP-mediated coagulation in the presence of all 3 substances, APC, heparin and ATIII. It was found that the PT was markedly prolonged only in the presence of the 3 substances (Figs. 2 and 3, Table I).
Ofosu et $a .^{27)}$ and Ellis et $a .^{28)}$ have reported that heparin abrogates thrombin-dependent activation of FV. However, such an effect was considered not to be-observed on the prolongation of the PT. Suzuki et al. ${ }^{29)}$ have reported that the inhibition rate of the purified $\mathrm{PC}$ inhibitor (PCI) was accelerated about 30-fold in the presence of relatively high-concentration heparin $(5 \mathrm{U} / \mathrm{ml})$. However, the influences of PCI and heparin were considered to be negligible in our present test system because the concentration of heparin was as low as $0.5 \mathrm{U} / \mathrm{ml}, 1 / 10$ that used by Suzuki et al., ${ }^{29)}$ and because the anticoagulation was accelerated by APC, heparin and ATIII as shown in Fig. 2.

Many workers have reported on the control of the TPmediated coagulation. ${ }^{30-32)}$ However, the regulation mechanism of the TP-mediated coagulation cascade reported herein is quite different from those reported so far: the coagulation cascade is strongly regulated by the cooperative effect among APC (a conventional anticoagulant factor), heparin and ATIII. The inactivation mechanism of the TPmediated coagulation cascade proposed by us can explain why the decrease of plasma ATIII and PC levels in patients with DIC causes severe disturbances in coagulation. ${ }^{\left.1{ }^{14}\right)}$ In addition, APC, heparin and ATIII formed complexes by weak binding as proved by two-dimensional immunoelectrophoresis and SDS-PAGE. This fact indicates that the in vivo inhibition of thrombin activity by ATIII-heparin complexes is regulated by APC and that there is a possibility of a weak negative feed-back mechanism in the inhibition of thrombin activity by APC (Figs. 3 and 4).

As shown in Table I and Fig. 5, the effect of APC with heparin was stronger than that of APC alone. These results suggest that the reduction of thrombin generation by the inhibition of prothrombinase by APC is enhanced by the presence of heparin, and finally ATIII and heparin efficiently inhibit thrombin activity.

Although the efficacy of the APC-ATIII-heparin mixture in a DIC animal model and the effect of protein $\mathrm{S}$ and thrombomodulin in our present experimental system remain to be confirmed, it can be said, if the TP-mediated coagulation cascade in vivo is regulated by ATIII, heparin and APC as suggested here, that the concomitant administration of the 3 substances should exhibit a potent anticoagulant effect in the treatment of DIC, provided that the activation of the coagulation cascade by the TP is one of the causes of DIC. ${ }^{3)}$ Development of a new preparation able to take the place of ATIII-heparin or containing ATIII, heparin and APC should provide an effective treatment of DIC.

\section{References}

1) M. Verstraete and J. Vermylen (ed), "Thrombosis," Pergamon Press, New York, 1984, p. 190.

2) M. Maki, T. Terao, T. Ikenoue, T. Kakemura, K. Sekiba, K Shirakawa and H. Souma, Gynecol. Obstet. Invest., 23, 230 (1987).

3) M. Brozović, "Haemostasis and Thrombosis," ed. by A. L. Bloom and D. P. Thomas, Churchill Livingstone Co., Edinburgh, 1987, p. 536.

4) E. W. Davie and D. J. Hanahan, "The Plasma Proteins," Vol. III, ed. by F. W. Putnam, Academic Press, New York, 1977, p. 421.

5) J. Stüerzebecher and F. Markwardt, Thromb. Res., 11, 835 (1977).

6) J. P. Miletich, C. M. Jackson and P. W. Majerus, J. Biol. Chem., 253, 6908 (1978).

7) T. Lindhout, D. Baruch, P. Schoen, J. Franssen and H. C. Hemker, Biochemistry, 25, 5962 (1986). 
8) F. A. Ofosu, A. L. Cerskus, J. Hirsh, L. M. Smith, G. J. Modi and M. A. Blajchman, Br. J. Haematol., 57, 229 (1984).

9) K. Hirahara, N. Ando, T. Matsuishi, N. Suzuki, T. Terao and M. Kurata, Yakugaku Zasshi, 108, 860 (1988).

10) K. Hirahara, T. Matsuishi, N. Suzuki and M. Kurata, Yakugaku Zasshi, 108, 867 (1988)

11) W. Kisiel, J. Clin. Invest., 64, 761 (1979).

12) H. Edelhoch, Biochemistry, 6, 1948 (1967).

13) H. Suzuki, "Jissen Shiketsu Gyoko-gaku (in Japanese, Practical Haemostasis-Coagulation)," ed. by M. Fujimaki, H. Terada and M. Kuwajima, Ishiyaku Shuppan Co., Tokyo, 1980, p. 102.

14) H. Löbermann, H.-J. Kolde, R. Deubel, R. Peter, E. Tourte and U. Becker, Behring. Inst. Mitt., 79, 112 (1986).

15) P. C. Comp and C. T. Esmon, Blood, 54, 1272 (1979)

16) N. Ressler, Clin. Chim. Acta, 5, 795 (1960).

17) R. D. Rosenberg and P. S. Domus, J. Biol. Chem., 248, 6490 (1973).

18) M. J. Griffith, J. Biol. Chem., 254, 12044 (1979).

19) P. C. Comp, Nouv. Res. Fr. Hematol., 26, 239 (1984).

20) J. H. Griffin, B. Evatt, T. S. Zimmerman, A. J. Kleiss and C. Wideman, J. Clin. Invest., 68, 1370 (1981).
21) F. J. Walker, P. W. Sexton and C. T. Esmon, Biochim. Biophys. Acta, 571, 333 (1979).

22) G. A. Vehar and E. W. Davie, Biochemistry, 19, 401 (1980).

23) P. C. Comp, R. M. Jacocks, G. L. Ferrell and C. T. Esmon, J. Clin. Invest., 70, 127 (1982).

24) K. Hirahara (unpublished data)

25) P. Lollar and W. G. Owen, J. Clin. Invest., 66, 1222 (1980).

26) J. T. Brandt, Clinics in Laboratory Medicine, 4, 245 (1984).

27) F. A. Ofosu, P. Sie, G. J. Modi, F. Fernandez, M. R. Buchanan, M. A. Blajchman, B. Boneu and J. Hirsh, Biochem. J., 243, 574 (1987).

28) V. Ellis, M. F. Scully and V. V. Kakkar, Adv. Exp. Med. Biol., 192, 373 (1985).

29) K. Suzuki, J. Nishioka, H. Kusumoto and S. Hashimoto, J. Biochem. (Tokyo), 95, 187 (1984).

30) S. D. Carson, J. Biol. Chem., 262, 718 (1987).

31) N. L. Sanders, S. P. Bajaj, A. Zivelin and S. I. Rapaport, Blood, 66, 204 (1985)

32) M. S. Bajaj, S. V. Rana, R. B. Wysolmerski and S. P. Bajaj, J. Clin. Invest., 79, 1974 (1987). 